Revista lus et Praxis, Año 21, No 1, 2015, pp. 137 - 170

ISSN 0717 - 2877

Universidad de Talca - Facultad de Ciencias Jurídicas y Sociales

"Un concepto de riesgo permitido alejado de la imputación objetiva"

Ítalo Reyes Romero

Trabajo recibido el 26 de septiembre y aprobado el 24 de diciembre de 2014

\title{
Un concepto de riesgo permitido alejado de la imputación objetiva*
}

\section{A NOTION OF ALLOWED RISK SEPARATED OF THE OBJECTIVE IMPUTATION}

ÍtALO ReYes ROMERO**

\section{RESUMEN}

El artículo se encarga de explicar tres ideas centrales. Primero, que un correcto entendimiento del concepto de riesgo permitido sólo puede ubicarlo estructuralmente en el análisis de la imprudencia, y por tanto, sin necesidad de establecer relación alguna con la teoría de la imputación objetiva. En segundo lugar, que por medio de un análisis del proceso de imputación (subjetiva) en general y de la imprudencia en especial, debe concluirse que esta última opera como un criterio de imputación extraordinaria. Y, finalmente, que el riesgo permitido tiene que entenderse como la permisión del ordenamiento a la limitación de la capacidad de acción basado en el presupuesto que no es posible prevenir todo riesgo.

\section{ABSTRACT}

The paper deals with three main ideas. First, that a right understanding of the notion of allowed risk can only be located in the analysis of negligence and, therefore, there are no need to establish any relation with the theory of objective imputation. Secondly, that by an analysis of the process of subjective imputation -in general- and of the negligence -in specific- must be concluded that the latter acts like a extraordinary imputation criterion. And, finally, that allowed risk needs to be understood like the normative permission to the restriction of action capacity, based in the assumption that there is impossible prevent every risk.

PALABRAS CLAVE

Imprudencia, Riesgo permitido, Imputación objetiva

KEYWORDS

Negligence, Allowed risk, Objective imputation

\section{El punto de partida: la contrafacticidad de la imputación}

Como bien señala el título del artículo, el objetivo de esta investigación está en proponer una noción del riesgo permitido alejada de la, así llamada, teoría de

\footnotetext{
* Este artículo tiene sus primeros lineamientos en un capítulo de mi memoria de licenciatura "Imprudencia y riesgo permitido: una clave de lectura del art. 10 № 8 del código penal" (disponible en línea en www.tesis.uchile.cl), dirigida por el profesor Juan Pablo Mañalich, a quien va dirigido un sincero agradecimiento por las numerosas correcciones y sugerencias.

** Investigador del Magíster de Derecho Penal, Universidad de Chile, Santiago, Chile. Correo electrónico: mdpinvestiga@derecho.uchile.cl.
} 
la imputación objetiva. Tal propuesta presupone una diferenciación estricta entre un proceso de subsunción del comportamiento bajo el tipo penal y un proceso de imputación de ese comportamiento a un determinado sujeto, todo ello bajo un modelo analítico de teoría de las normas. Se sostendrá que en este proceso de imputación de la conducta típica y los criterios que se utilizan para tal atribución, se encuentra el espacio conceptual para fundamentar un concepto de riesgo permitido coherente con la sistemática de la teoría del delito en su conjunto.

Ahora bien, antes de continuar con la argumentación, es necesario hacer explícita la premisa que subyace a la comprensión del proceso de imputación como el reconocimiento de la capacidad del sujeto de evitar, mediante su acción u omisión, el quebrantamiento de la norma penal de comportamiento ${ }^{1}$. Porque, desde un punto de vista jurídico penal, lo interesante es determinar si un sujeto ejecutó una conducta típicamente relevante estando capacitado para no ejecutarla, pues en esos términos la ejecución de tal conducta manifiesta una falta de fidelidad al ordenamiento jurídico o, que es lo mismo para estos efectos, el desconocimiento de la vigencia de esa norma ${ }^{2}$. La caracterización es entonces negativa: el sujeto realizó una acción que no debía realizar si hubiese sido fiel a derecho, por lo que la ejecución de esa conducta conlleva una contradicción con la validez del ordenamiento y merece el reproche objetivado en una pena.

La negatividad del objeto de referencia del proceso de imputación se deja expresar con mayor claridad en la forma de un silogismo práctico ${ }^{3}$. Esta herramienta lógica permite concluir lo que un sujeto debe realizar o dejar de realizar -con necesidad práctica- para el seguimiento de una determinada voluntad de acuerdo a sus conocimientos sobre el mundo ${ }^{4}$. En al ámbito jurídico penal, la cuestión a determinar consiste en si la conducta ejecutada expresa una falta de fidelidad al ordenamiento, por lo cual resulta necesario establecer qué era lo que un ciudadano fiel a derecho hubiese debido realizar o dejar de realizar en las circunstancias específicas de la actuación ${ }^{5}$. En

\footnotetext{
1 Para la diferenciación entre normas de comportamiento y normas de sanción, véase MAÑALICH (2010), pp. 172 y s.

2 KINDHÄUSER (2008), p. 8.

3 Para mayor información sobre el silogismo práctico, véase VON WRIGHT (2008), especialmente interesante es la diferencia entre inferencias de primera y tercera persona (pp. 309 y ss.), debiendo entenderse que en la imputación jurídico penal sólo reclama relevancia la de primera persona, con el objeto que la conclusión tenga necesidad práctica.

${ }^{4}$ VON WRIGHT (2008), p. 304, donde se explican en general los componentes lógicos de una inferencia práctica y pp. 309 ss., en donde se discute el contenido de la premisa menor de una inferencia de primera persona.

${ }^{5}$ KINDHÄUSER (2008), pp. 9 y s., quien entiende que la premisa mayor consiste específicamente en "la evitación de la realización del tipo como el objetivo jurídicamente obligatorio", lo cual otorga mayor relevancia a la disposición volitiva del ciudadano fiel a derecho. En mi opinión, la premisa mayor debe
} 
tal sentido, la premisa mayor tiene que estar constituida por la norma penal que se somete a estudio y que cuenta como razón para la acción ${ }^{6}$ de un ciudadano que tiene una voluntad de seguimiento del derecho. Ésta es la única voluntad que puede resultar interesante a efectos de la imputación pues es la que permite determinar la eventual discrepancia entre lo que debía realizar el sujeto y lo que efectivamente realizó y que legitima el reproche. Luego, la premisa menor tiene que incorporar los conocimientos y capacidades relevantes del sujeto según el contexto de actuación. Esto porque no nos importa la conducta que un ciudadano fiel a derecho cualquiera hubiese realizado sino, por el contrario, lo que debía realizar o dejar de realizar el específico autor de haber reconocido validez al ordenamiento. De tal manera, la conclusión práctica indicará el deber de ejecutar o abstenerse de ejecutar una determinada acción, deber que está vinculado con una voluntad de fidelidad al derecho. Si el sujeto, por el contrario, efectivamente realizó o no se abstuvo de la acción exigida, entonces la imputación es exitosa porque la conducta objetivamente contraria a la norma se entiende como suya, evidenciando el desconocimiento de esa norma como razón para la acción ${ }^{7}$.

A modo de ejemplo, si A dispara a B causando su muerte, entonces lo que nos interesa conocer es si A contaba con la capacidad para evitar la realización de la conducta letal. Si contaba con tal capacidad, entonces una voluntad de fidelidad al ordenamiento le exigía abstenerse de disparar contra B. Dado que efectivamente disparó a B, entonces ha infringido ese deber de abstención por lo cual se afirma el quebrantamiento imputable de la prohibición del homicidio por parte de A. Sin embargo, es perfectamente posible plantear que A carecía de capacidad de evitación porque, por ejemplo, se representó estar disparando a un espantapájaros. En atención a ese error, no es posible concluir el deber de A de abstenerse del disparo en atención a la prohibición del homicidio, pues tal acción no compromete su voluntad de seguimiento de la norma ${ }^{8}$.

enfatizar la vigencia del derecho, bastando simplemente la norma de comportamiento puesto que, al asumir las normas como razones para la acción, la disposición volitiva del agente queda implícita.

6 Para mayor detalle sobre las normas como razones para la acción, véase RAz (1975), pp. 73 y ss. RAz (1986), pp. 259 y ss. Basta mencionar aquí que, según Raz, las normas obligatorias (mandatory rules) deben ser entendidas como razones excluyentes (exclusionary reason), esto es, razones de segundo nivel que excluyen la fuerza de razones de primer nivel.

7 Véase MAÑALICH (2014), p. 24, quien plantea que el deber individual que se deriva de una norma de comportamiento (o de mandato) tiene como presupuesto que tal norma sea reconocida por su destinatario como razón para ejecutar (u omitir) la acción en cuestión.

${ }^{8}$ Por supuesto, tal conclusión aún no se refiere a la posibilidad de imputar el comportamiento a título de imprudencia, lo cual será analizado posteriormente. 
Lo crucial es advertir, entonces, lo negativo del proceso de la imputación derivado de un principio de contrafacticidad del mismo ${ }^{9}$ : se verifican las capacidades del sujeto al momento de ejecutar la conducta típica con la finalidad de establecer que éste hubiese podido comportarse de una manera adecuada a derecho, de modo que la ejecución de tal conducta típica expresa no solamente una contradicción objetiva con el ordenamiento sino también una falta de reconocimiento subjetivo del mismo ${ }^{10}$. Así, el principio de contrafacticidad de la imputación se concreta en el reconocimiento de una capacidad de evitación del comportamiento que satisface la descripción típica, pues comprobando tal capacidad es posible afirmar que el agente podía actuar conforme a las normas jurídico penales y, en efecto, decidió (libremente) no hacerlo, oponiendo su voluntad individual a la voluntad general del derecho ${ }^{11}$.

Para terminar este punto de partida, valga señalar que este principio subyace a todo el esquema de imputación, tanto a título de dolo como a título de imprudencia, pues ambos criterios están comprometidos con el reconocimiento de una capacidad de evitación de la realización típica. Será, eso sí, en el estudio de la imprudencia donde se defenderá la incorporación de una noción de riesgo permitido, pero ahora alejada de la teoría de la imputación objetiva. En tal sentido, se hace necesario, primero, esbozar las dificultades que implica entender el riesgo permitido en ese enclave.

\section{Los problemas del riesgo permitido en la teoría de la imputación objetiva}

Pudiera pensarse que existe un acuerdo casi unánime en la doctrina penal que el concepto de riesgo permitido está inexorablemente ligado a la teoría de la imputación objetiva como uno de los pilares elementales de su esquema de imputación. Porque, como bien expone quien la hizo internacionalmente popular, "un resultado causado por el agente sólo se puede imputar al tipo objetivo si la conducta del autor ha creado un peligro para el bien jurídico no cubierto por

\footnotetext{
${ }^{9}$ Véase Mañalich (2014), pp. 26 y ss., con ulteriores referencias.

10 Si bien no se explicita el principio de contrafacticidad, igualmente subyace al argumento de KINDHÄUSER (2008), pp. 10 y s.: "dado que el autor parte de una situación fáctica que le habría hecho prácticamente necesario ejecutar u omitir una acción para él posible, para evitar así la realización de un tipo delictivo, en circunstancias que él, de hecho, no ejecutó u omitió esta acción, queda entonces establecido que él no quiso realizar el objetivo, fijado por la norma, de evitar la realización del tipo, a pesar que él habría podido realizador, esto es, que él no quiso hacer lo que debía" (el destacado es mío). Asimismo, en KINDHÄUSER (2011), p. 77 se revisa la importancia de la alternativa contrafáctica para que podamos hablar ya de una acción (desde un punto de vista adscriptivo).

11 De acuerdo con Mañalich (2014), pp. 24 y s., la conclusión de que el autor no reconoció subjetivamente a la norma como razón para la acción tiene la forma de un argumento destructivo en modus tollendo tollens, cuya estructura es: Si $p$, entonces $q$ / no $q$ / entonces, no $p$.
} 
un riesgo permitido y ese peligro también se ha realizado en el resultado"12. La noción de riesgo, por ende, deviene en esencial, pero no tanto como cualidad de la acción (en el sentido de acción riesgosa) sino más bien como efecto de esa acción (en el sentido que la acción produce un riesgo). Para hablar de injusto objetivo, entonces, resulta imprescindible que la acción deba crear un riesgo que se realice en un resultado típico y que ese riesgo deba ser no permitido ${ }^{13}$.

El carácter no permitido del riesgo tiene que determinarse objetivamente, esto es, sin atender a circunstancias individuales del autor pues el juicio de imputación objetiva está comprometido con un destinatario promedio fiel a derecho ${ }^{14}$ quien cuenta con conocimientos y capacidades también promedio. Entonces si la permisión del riesgo no puede depender de la manera en la que el sujeto ha realizado la conducta riesgosa -pues tienen que excluirse sus capacidades y conocimientos-entonces su determinación como riesgo permitido tiene que ser necesariamente general. Así lo reconoce Roxin al señalar que "aquí se va a entender por riesgo permitido una conducta que crea un riesgo jurídico penalmente relevante, pero que de modo general (independiente del caso concreto) está permitida"15. Esto implica que el criterio de riesgo permitido opera con independencia del hecho específico que se analiza, de modo que cualquier característica concreta es irrelevante: en definitiva, sólo importa la clase de conducta que se ejecuta. En otras palabras, el riesgo permitido no tiene que ver con la ejecución de una acción por parte de un sujeto sino más bien con la ejecución de un tipo de acción.

Ahora bien, entendiendo la importancia que la teoría de la imputación objetiva atribuye al concepto de riesgo permitido al excluir ya la posibilidad de reconocimiento de un injusto objetivo, la interrogante inmediata tiene que versar sobre la justificación de la permisión de ese riesgo. Y aquí existe algún consenso en que esa permisión se basa en una ponderación de intereses, en el que los beneficios generales que se derivan de la ejecución de una determinada actividad entregan un permiso al riesgo de resultado lesivo que genera esa actividad $^{16}$. El

12 Roxin (1997), p. 363. Asimismo, Roxin indica que el otro principio fundamental de imputación objetiva consiste en una excepción: "Si el resultado se presenta como realización de un peligro creado por el autor, por regla general es imputable (...) Pero, no obstante, excepcionalmente puede desaparecer la imputación si el alcance del tipo no abarca la evitación de tales peligros" (p. 364). Este criterio atiende a la problemática de fin de protección de la norma. Para mayor detalle, véase Roxin (1997), pp. 377 y s.

13 Para profundizar el concepto de riesgo permitido en la teoría de la imputación objetiva y, especialmente, revisar su conexión con el principio de confianza, véase Corcor (1989), pp. 308 y ss.

14 KINDHÄUSER (2008), p. 10.

15 Roxin (1997), p. 371 (el destacado es mío). En el mismo sentido, JakOBS (1995), p. 250.

16 Así, JAKOBS (1995), p. 243, para quien tal ponderación no se realiza tomando en cuenta solamente un patrón técnico (económico), el cual sirve para determinar lo que es usual o preferible, pero el 
análisis coste-beneficio resulta fundamental a la hora de determinar lo que la sociedad ha tolerado en virtud de la utilidad recibida. Entonces, la permisión se justificaría en torno a intereses superiores de bien común frente a los posibles perjuicios individuales. Pero, dado el destinatario que se tiene en cuenta en este juicio de imputación puramente objetiva, no interesa el caso concreto, como sí interesaría, por ejemplo, en la ponderación de intereses del estado de necesidad, en donde la decisión de justificación se toma analizando las circunstancias concretas de actuación ${ }^{17}$. Aquí basta una ponderación global de los costes y beneficios involucrados que excluye la posible tipicidad de la acción ${ }^{18}$.

Revisemos un caso resuelto en atención al riesgo permitido planteado por el mismo Jakobs: "Todo fabricante de vehículos automóviles (aunque lo haga correctamente) es causante, por la fabricación de todos los accidentes en que intervenga un vehículo suyo, sin que la fabricación se convierta por ello en un suceso que sea tolerable sólo en relación a un contexto justificante" ${ }^{\prime 19}$. El argumento es que el fabricante no puede ser entendido por responsable de algún accidente en que esté involucrado alguno de sus vehículos, a menos que exceda el riesgo permitido, por ejemplo incorporando frenos en mal estado. Más allá de la discusión sobre causalidad ${ }^{20}$, lo interesante es que el fundamento de la permisión parece estar en que la fabricación de automóviles es una actividad socialmente permitida, de manera que los riesgos que se derivan de ella deben entenderse también como permitidos. Y, por tanto, solamente se excluye tal permisión cuando se excede el riesgo pues la actividad cambia a una de fabricación de vehículos en mal estado, la cual no puede ser tolerada.

problema de valoración se resuelve acudiendo a baremos jurídicos, en el sentido de si hablamos de intereses jurídicamente reconocidos o no. En el mismo sentido, Roxin (1997), p. 372, quien entiende la conducción vehicular como un caso de ponderación de intereses.

17 Roxin (1997), p. 372.

18 Para Corcor (1989), pp. 311 y ss., la fundamentación del riesgo permitido depende de cuatro grupos de casos en los cuales este concepto cobraría relevancia. El primer grupo de casos se relaciona con la utilidad social y parece ser el único ámbito donde Corcoy (p. 319 y s.) entiende como adecuado hablar de riesgo permitido. Los demás casos - causalidad imprevisible, salvación arriesgada y consentimiento en el riesgo- estarían relacionados con otros elementos constitutivos del hecho punible.

19 JAKOBS (1995), p. 245.

${ }^{20}$ El argumento de que cada vez que un vehículo producido por el fabricante produzca algún accidente se puede establecer un vínculo causal con la fabricación de ese mismo vehículo desconoce el recurso conceptual al campo causal. Esto es, toda explicación de causalidad tiene que tomar como presupuesto un número extenso de circunstancias, pues de lo contrario la explicación se vería sistemáticamente frustrada. Por ejemplo, si A mata a B, siguiendo el argumento de Jakobs, podríamos establecer un vínculo causal con los padres de A debido a su procreación. Empero, tal circunstancia es irrelevante en este contexto porque está presupuesta como campo causal. Para más detalles, véase MAÑALICH (2014), pp. 46 y s., con ulteriores referencias. 
No obstante, del hecho que una determinada actividad entregue beneficios sociales no se deriva una permisión general a la ejecución de conductas que se enmarcan dentro de esa actividad. Es así que la venta de comida en un restaurante es una actividad que, podríamos decir sin miedo a equivocarnos, está permitida. Sin embargo de ese hecho no se debe derivar consecuencia alguna respecto de una eventual imputación de delito. Porque si el cocinero no detecta que uno de sus ingredientes está en mal estado y eso lleva a lesiones menos graves de los comensales, entonces el cocinero no puede defenderse diciendo que la actividad que realiza es una socialmente permitida. Tal argumentación conlleva un desconocimiento de la forma en que opera la imputación penal. Pues si hay una relación de causalidad establecida entre el comportamiento -ahora específico- del sujeto y la realización de un tipo delictivo entonces lo único que debiera interesarnos es si acaso podemos atribuir esa conducta lesiva al sujeto. Que la actividad que desempeña entregue más o menos beneficios sociales no tiene relevancia alguna a este efecto.

Entonces, el reconocimiento de un comportamiento como penalmente desaprobado no puede depender de su inclusión en una categoría más amplia de actividad ilícita. Si el carácter permitido del riesgo creado por la conducta depende de los costos y beneficios objetivos que trae aparejada la realización de la actividad social que abarca a esa conducta, entonces el criterio penalmente relevante tendría que estar en la posibilidad de diferenciar con exactitud la clase de acciones que generan riesgos permitidos y la clase de acciones que no los generan, pues sólo en esta última podría ser exitosa una imputación en el tipo objetivo ${ }^{21}$.

$\mathrm{Y}$ aunque aceptáramos esa incorrecta premisa sigue siendo sumamente complejo determinar el nivel de concreción de cada categoría. Piénsese en el ejemplo ya descrito: la actividad de un restaurante de servir comida es generalmente lícita lo cual conllevaría la impunidad del cocinero descuidado. Sin embargo, aún podríamos decir que en el ejemplo no se realiza esa actividad sino más bien la actividad de servir comida en mal estado, la cual evidentemente no está permitida. La pregunta que surge es cómo determinar el nivel de concreción de la actividad para evaluar su permisión. Y la respuesta no puede ser sino excesivamente compleja al necesitar incorporar una serie de criterios extrínsecos ${ }^{22}$. El punto es que tal pregunta es completamente innecesaria si es

${ }^{21}$ Como ejemplo de la confusión que incorpora la noción de riesgo permitido desde la teoría de la imputación objetiva, puede revisarse Ovalle (2011), pp. 3 y s., quien discute sobre la posibilidad de verificar imprudencia en escenarios de riesgos permitidos, lo cual muestra lo débil que puede llegar a ser esa comprensión en el seno de tal teoría.

${ }^{22}$ La misma dificultad se enfrentan aquellos que defienden una postura "generalizadora" del contenido del deber de cuidado, pues al determinar la imprudencia en atención a un observador con capacidades y conocimientos promedio se hace necesario construir sectores del tráfico sumamente 
que atendemos al específico comportamiento del sujeto, pues en este nivel tenemos un punto de referencia indiscutido, a saber: la descripción típica. Por tanto, la dificultad se desvanece si centramos el análisis en la única cuestión que interesa desde el punto de vista jurídico penal: la conducta efectivamente realizada. De tal forma, no existen problemas de determinar qué actividades están permitidas y cómo determinamos lo que llamamos actividad. El punto está en que lo importante no puede ser si la clase de acción que realiza el sujeto es $\mathrm{X}$ o $\mathrm{Y}$ sino si el comportamiento efectivamente ejecutado por el sujeto se subsume en el tipo penal o no.

Entonces, dada las dificultades que enfrenta un concepto de riesgo permitido en el seno de la teoría de la imputación objetiva, la finalidad de esta investigación es proveer una definición lejana de esa teoría. Desde este punto de vista, un concepto como el que será planteado no se opone todavía a la generalidad de la teoría de la imputación objetiva sino que más bien toma un camino alternativo para definir los ámbitos individuales de responsabilidad. Sin embargo, en el fondo, esta noción está comprometida con la comprensión del injusto objetivo sólo como un proceso de subsunción, esto es, en que lo único relevante es que el comportamiento satisfaga los elementos descritos en el tipo sin la necesidad de incorporar filtro objetivo alguno.

\section{La imputación a título de imprudencia}

En lo que sigue, se defenderá que un correcto entendimiento del concepto de riesgo permitido sólo puede ubicarse estructuralmente en el análisis de la imprudencia. Y ello implica, por tanto, revisar primeramente $-y$ por ahora, escuetamente- la noción de imprudencia, a saber: un criterio de imputación (subjetiva) extraordinaria.

El análisis del injusto se encuentra tradicionalmente dividido entre el ámbito objetivo y el ámbito subjetivo. Si bien esa demarcación no es estrictamente precisa, nos es útil para explicitar los diversos procesos lógicos que se realizan en cada ámbito. Esto porque lo relevante del injusto objetivo está en comprobar que la conducta efectivamente ejecutada realiza el contenido proposicional de una determinada norma. Es decir, que la conducta que ejecuta el sujeto es una concreción -de las tantas posibles- de la descripción típica. Ese proceso se denomina subsunción pues implica considerar el comportamiento como particularización de la norma. En tal sentido, será esa descripción típica la que determine los elementos relevantes a tener en consideración en la con-

complejos de delimitar. Véase, Roxın (1997), pp. 1009 y 1017. En contra de un modelo generalizador y a favor de uno individualizador del contenido de la exigencia de cuidado, véase VAN WeEzeL (1999) y Van WeEZel (2011). 
ducta del sujeto. Si la prohibición del homicidio se deja entender como "está prohibido matar a otro", lo único relevante para hacer aplicable esa norma es si alguien mató a otra persona. Que lo haya hecho por venganza o por celos, debe sernos completamente irrelevante a la luz de tal descripción típica.

Así, tener por configurado el injusto objetivo simplemente pone en evidencia la contradicción entre una norma y la forma de realización de una conducta. Es decir, implica aseverar que ella es antinormativa ${ }^{23}$, aunque sin interesar todavía la posibilidad de imputación de esa conducta en virtud de las capacidades del sujeto. Y este juicio de subsunción debe realizarse siempre asumiendo una perspectiva ex post ya que se requiere observar toda la información sobre la ocurrencia del hecho, y no solamente con la que contaba el autor al momento de emprender la acción ${ }^{24}$. En los delitos de resultado, por supuesto, tal subsunción tiene que dar cuenta del vínculo causal entre la conducta de un sujeto y los acontecimientos acaecidos en el mundo ${ }^{25}$.

Ahora bien, el ámbito subjetivo del injusto atiende tradicionalmente al estudio del dolo y de la imprudencia. Sin embargo, lo que está detrás de ambas categorías es la posibilidad de atribuir la conducta que realiza la descripción típica a un determinado sujeto. Es decir, determinar si el autor contaba con las capacidades necesarias para el seguimiento de la norma, de modo que si contaba con ellas e igualmente ha ejecutado el comportamiento antinormativo, queda legitimado (en principio) un reproche en su contra. Sólo así es posible observar la contradicción entre la voluntad subjetiva del sujeto, objetivada en su comportamiento, y la voluntad general del ordenamiento.

El proceso de imputación se realiza en virtud de ciertos criterios o reglas que otorgan contenido a la respuesta punitiva por el comportamiento demeritorio y que varían respecto del ámbito de imputación ${ }^{26}$. Lo importante es diferenciar con precisión entre objeto y criterio de imputación. El objeto de la imputación

23 MaÑALICH (2010), p. 176.

${ }^{24}$ Mañalich (2010), pp. 176 y 183.

25 En el mismo sentido que Puppe (2008), pp. 13 y ss., 41 y s., aquí se entiende que la causalidad no está dada solamente cuando "una conducta es condición necesaria del resultado; [sino] basta con que sea parte integrante de una condición mínima del resultado, efectivamente cumplida y suficiente según leyes naturales". De tal modo se sostiene como correcta una teoría de equivalencia de las condiciones -en oposición a una teoría de "causalidad adecuada" - aunque la fórmula de condición necesaria (conditio sine qua non) presenta problemas irresolubles frente a casos de causalidad alternativa. En tal sentido, se hace necesario acudir a un concepto de condición mínimamente suficiente, la cual no presenta contradicción en invocar más de una condición compleja para explicar el resultado. Para más detalle, véase Mañalich (2014), pp. 39 y ss., con numerosas referencias ulteriores.

${ }^{26}$ Hruschka (2009c), pp. 14 y ss. Véase también, Pérez del Valle (2012), pp. 143 y s. 
es el comportamiento que realiza la descripción típica ${ }^{27}$. En cambio, el criterio de imputación tiene que ver con el reconocimiento de capacidades que permiten adscribir ese comportamiento antinormativo al sujeto. Esto implica que la verificación del injusto objetivo es autónoma frente al reconocimiento de criterios subjetivos pues se alude a diferentes procesos lógicos que operan de manera distinta. Ello no excluye, por supuesto, que la imputación verse sobre el comportamiento subsumido en el tipo penal.

La imputación en el nivel de injusto -denominada de primer nivel ${ }^{28}$ - conlleva la adscripción de un cierto hecho como acción de ("perteneciente a") un sujeto. Afirmar la imputación de primer nivel respecto de alguien cuenta como que el autor "ha estado en situación de omitir el hecho comisivo imputado o bien de ejecutar el hecho omitido" 29 . Por tanto, este primer nivel apunta a la evitabilidad del comportamiento analizado: la acción es libre, entendiendo la libertad como Aristóteles, esto es, en palabras de Hruschka, "una acción es 'libre' (y con ello realizada 'con volición') cuando el 'origen' de la acción reside en el propio agente y éste conoce las circunstancias relevantes de la acción" ${ }^{\prime 30}$.

En otras palabras, sostener que un determinado hecho es atribuible en este primer nivel a un sujeto es reconocerle-en nomenclatura actual-capacidad de acción: el sujeto presenta las condiciones físicas e intelectuales (cognitivas) con las cuales pudo haber evitado la comisión del hecho ${ }^{31}$. En la medida que esas condiciones implican que el sujeto estuviese en posición física de actuar distinto y que además tuviese el conocimiento suficiente sobre las circunstancias de su actuar, aquí el criterio de imputación relevante es el dolo ${ }^{32}$. Entonces quien se comporta dolosamente se encuentra en posición de actuar conforme a la norma de prohibición o de mandato respectivo, pues le es evitable tanto física como cognitivamente su infracción, de forma que si el autor ejecuta una acción que

\footnotetext{
${ }^{27}$ Correctamente Ovalle (2011), p. 5, quien reconoce que la verificación de la causalidad es integrante del objeto de la imputación.

${ }^{28}$ De acuerdo con HruschKa (2009c), pp. 16 y ss. la imputación se da en dos niveles: la de primer nivel está relacionada con la posibilidad de entender el comportamiento como "algo que ha hecho un sujeto agente" (p. 16), mientras que la de segundo nivel es un juicio sobre el demérito, esto es, sobre la culpabilidad del autor (p. 21). De tal forma, la imputación de primer nivel permite hablar sobre la capacidad de acción del sujeto para evitar la realización típica; y la de segundo nivel sobre su capacidad de motivarse a evitar la realización típica.

${ }^{29}$ HRUSCHKA (2009C), p. 16.

30 HRUSCHKA (2009a), p. 201, nota 3.

31 Mañalich (2010), pp. 179 y s.

32 KINDHÄUSER (2013), p. 220. Evidentemente una postura como la señalada asume una posición cognitiva del dolo. Para una revisión tradicional de las teorías al respecto, véase GarRIDO MONTT (2005), pp. 78 y ss.; para una revisión dogmática más detallada, véase RAGUÉs (1999), pp. 189 y ss.; para una revisión de la jurisprudencia nacional al respecto, véase VAN WeEZeL (2012), pp. 6 y ss.
} 
realiza la descripción típica está expresando con ello su negativa al seguimiento de la norma, en definitiva, una voluntad de negación del derecho. Por ello, aseveramos que esa conducta es antijurídica, o sea, contraria al ordenamiento jurídico; y que el sujeto ha infringido su deber de evitarla ${ }^{33}$.

Por consiguiente, si el sujeto carece de la capacidad para evitar la realización típica, de modo que, en el momento relevante, le era imposible ejecutar un comportamiento adecuado a deber, el dolo tiene que ser descartado. En ese sentido, la imputación en principio fracasa porque no es posible atribuir la conducta al sujeto ya que éste carece de capacidad de evitación. Sin embargo, aún podemos preguntarnos por la razón por la cual el sujeto carece de la capacidad para evitar el resultado lesivo, es decir, por qué no hay dolo. La pregunta es interesante pues es posible desarrollar acciones que aseguren la capacidad futura, en el sentido que se pretenda evitar quedar en una situación de inevitabilidad. En otras palabras, quien asuma las normas penales como razones para la acción, no sólo puede interesarle evitar la ejecución de acciones que provoquen resultados típicos, sino también evitar una situación en la cual no podrá evitar ese resultado típico. De tal forma, el examen de esta "evitación de la inevitabilidad" se corresponde con el estudio de la imprudencia: el que actúa conforme a cuidado asegura su capacidad para evitar la infracción del deber ${ }^{34}$.

Lo relevante está en notar la relación entre el dolo y la imprudencia, lo cual se deja reconstruir en la diferenciación entre dos tipos de imputación. La imputación ordinaria se refiere a cuando el agente está en condiciones de evitar la producción del resultado, o sea, es la imputación que atiende a las capacidades de primer o segundo nivel para que el autor, en definitiva, se motive y evite la realización de esa acción. La imputación extraordinaria, por el contrario, ocurre "cuando en el momento decisivo la persona en cuestión no está en condiciones de evitar la producción del suceso o de realizar la acción en cuestión, pero puede reprochársele precisamente que se encuentre en esta situación de imposibilidad o de incapacidad"35.

\footnotetext{
${ }_{33}$ Aquí puede ser útil volver al silogismo práctico. Véase KINDHÄUSER (2008), pp. 9 y s., quien correctamente plantea que el dolo se corresponde con la premisa menor que manifiesta los conocimientos del sujeto sobre el mundo y que eran relevantes para seguir la norma de comportamiento específica. Sólo en atención a esos conocimientos se puede afirmar si el sujeto tenía (o no) el deber de evitar ejecutar una determinada acción, es decir, si libremente decidió contravenir la norma. En un sentido similar, pero dotando al silogismo práctico de menor relevancia, Pérez Del Valle (2012), pp. 157 y s.

${ }^{34}$ En un sentido similar, Ovalle (2011), pp. 5 y s. Asimismo, Pérez Del Valle (2012), pp. 86 y s., quien reconoce, por tanto, la radical importancia de la parte especial para un análisis adecuado de la imprudencia.

35 Hruschka (2009b), p. 55. Por su parte, Pérez del Valle (2012), p. 145 y ss. critica la comprensión de la imprudencia como una forma de imputación extraordinaria pues señala que "la imputación de la imprudencia es regular, y no por excepción: la imprudencia tiene un contenido concreto y no significa
} 
De tal modo, si el sujeto carece de la capacidad cognitiva necesaria para la evitación de la conducta lesiva no existirá dolo, pero aún podemos imputar extraordinariamente haciendo responsable al autor precisamente por esa ausencia de dolo en los casos en que esa incapacidad no haya sido evitada por el sujeto. Por ejemplo, supongamos que $A$ tiene relaciones sexuales consentidas con $B$, una menor de 12 años, pero $A$ supone que la menor tiene 15 años. Esto implica que A está incapacitado, en el momento relevante, para evitar la realización del tipo de la violación impropia (art. 362). Sin embargo, resulta sensato preguntarnos si A podía haber asegurado su capacidad de evitación futura ejecutando una medida básica de cuidado, por ejemplo, preguntarle la edad a B. Al no hacerlo, entonces $\mathrm{A}$ ha actuado con imprudencia ${ }^{36}$. Nótese que esta imputación a título de imprudencia sólo es posible cuando no puede afirmarse la imputación ordinaria porque "solamente cuando algo no está a mi alcance en el momento decisivo puede plantearse si yo soy quizá responsable de que ya no esté a mi alcance ${ }^{\prime \prime 37}$.

Entonces, lo interesante es observar que la imputación a título de imprudencia se conecta con una capacidad "secundaria" de evitación de la realización típica, en contraposición con la imputación a título de dolo que evidencia una capacidad "primaria" de evitación ${ }^{38}$. Y es secundaria porque en la imprudencia se evalúa la capacidad para evitar una situación en la que sea inevitable la ejecución de una conducta típica, de manera que la cuestión a resolver está en un orden conceptualmente distinto al de la pregunta sobre el dolo. Por tanto, en atención a esta diferente capacidad asociada, es que no puede afirmarse una diferencia puramente cuantitativa entre dolo e imprudencia ${ }^{39}$, pues la diferencia está ya en los diversos espacios lógicos en que podemos hablar de uno u otro criterio.

simplemente excepción al dolo o ausencia de dolo" (p. 148). La cuestión se resuelve, sin embargo, si entendemos que lo extraordinario tiene que entenderse no como imputación irregular sino como imputación secundaria, esto es, que depende conceptualmente de la exclusión de la imputación primaria. Ello, por supuesto, es completamente independiente de la discusión sobre el contenido de la exigencia de cuidado.

${ }^{36}$ A este respecto, resulta irrelevante que no existan casos de violación imprudente tipificados en nuestro ordenamiento, porque lo que se trata de justificar es si se infringió imputablemente una norma y no si efectivamente el sujeto será sancionado por tal infracción. Es decir, estamos en el marco conceptual del delito y no del hecho punible. Para mayor detalle, véase Mañalich (2011), pp. 89 y ss.

37 HRUSCHKA (2009b), p. 79.

38 En el mismo sentido, Pérez Del Valle (2012), p. 145.

${ }^{39}$ En contra, véase Molına (2011), pp. 5 y ss., quien sostiene que dolo e imprudencia no serían "escalones independientes" sino "dos términos referidos a una misma propiedad, relativa al conocimiento por parte del autor de la peligrosidad de su acción para el resultado típico, siendo esta propiedad perfectamente gradual". Es necesario tener presente que este autor plantea, en definitiva, la imposibilidad de distinguir conceptualmente entre dolo eventual e imprudencia consciente. Tal conclusión es, en último término, el resultado al que debiese llegar toda teoría que sinceramente afirme una diferencia meramente cuantitativa entre dolo e imprudencia. 
Por tanto, se determina que el sujeto es responsable por el hecho, no basado en la capacidad que tenía en el momento de su ejecución, sino por la capacidad que podría haber tenido si hubiese actuado previamente atendiendo al seguimiento futuro de la norma. En definitiva, se imputa que el sujeto no se hubiese comportado de la manera que evitaba esa incapacidad, es decir, de una manera adecuada que evitaría la afectación de bienes jurídicos a través de acciones futuras que escapasen a su control. En otras palabras, si el autor se hubiese comportado cuidadosamente entonces podría haber mantenido la capacidad para evitar la infracción de la norma. Y ese cuidado le era exigido normativamente puesto que una acción contraria a cuidado también expresa una voluntad de negación del derecho, aunque claramente en un sentido más débil que el dolo (que expresaría una "voluntad directa" de negación). La conducta imprudente expresa, por tanto, la aceptación del riesgo de contradicción del derecho por incapacidad de controlar su propia acción futura ${ }^{40}$.

Y en la imprudencia, entonces, el criterio de imputación correspondiente se encuentra en la infracción de una exigencia de cuidado ${ }^{41}$, en el sentido que si el sujeto pretende mantener su capacidad de seguimiento futuro de la norma debe actuar de acuerdo esa exigencia, siendo su quebrantamiento la razón por la cual entendemos infringido el deber de acción respectivo y, por tanto, configurado el injusto subjetivo ${ }^{42}$.

Ahora bien, al asumir que la imprudencia está comprometida con el aseguramiento de la capacidad futura de evitación, entonces se hace necesario que el autor realmente hubiese podido evitar el resultado si se hubiese comportado conforme a cuidado. Es decir, la exigencia de cuidado no tiene como propósito la efectiva evitación del resultado típico sino simplemente que el autor quede en situación de actuar conforme a deber. Mientras el dolo tiene como función la evitación del resultado típico que evidencia una falta de motivación leal a derecho, con la imprudencia, el derecho penal pretende asegurar que, en el momento preciso, el sujeto pueda motivarse lealmente a derecho, no que efectivamente se evite el resultado típico.

Ello implica que no es posible exigir, como lo hace la doctrina nacional clásica, un vínculo causal entre la realización del tipo y la infracción de la

\footnotetext{
${ }^{40}$ En un sentido similar, KINDHÄUSER (2013): "Un no-saber también puede expresar un déficit de reconocimiento de la norma, si el correspondiente saber hubiese capacitado al autor para la evitación de la realización del tipo".

${ }^{41}$ Véase, VAN WeEzel (1999), pp. 332 y ss. (VAN WeEzel (2011), pp. 142 y ss.) para un análisis del contenido de la exigencia de cuidado desde una correcta posición individualizadora.

${ }^{42}$ Mañalich (2010), p. 180. Para una revisión de la evolución histórico-dogmática del concepto de deber de cuidado, véase Pérez Del Valle (2012), pp. 75 y ss. Para una revisión del concepto de deber de cuidado especificado en el ámbito médico de acuerdo a la lex artis, véase Rosas (2011), pp. 5 y ss.
} 
exigencia de cuidado $^{43}$. Lo relevante no es que el resultado haya sido causado por la infracción del cuidado, de modo que si el sujeto se hubiese comportado con la diligencia debida, entonces el resultado típico no habría tenido lugar. En el ejemplo de un hombre que imprudentemente maneja un arma por lo cual se escapa un disparo que hiere a otro, la doctrina clásica exigiría la comprobación de que la lesión del último fue causada por la vulneración de las normas de cuidado pertinentes por parte del primero. El problema es que no es posible aseverar con necesidad causal que el resultado lesivo no se hubiese producido de haber cumplido con los estándares de cuidado. Porque es perfectamente posible que el sujeto igualmente hubiese ejecutado la acción en el mismo momento, ahora dolosamente, provocando el mismo resultado. Y si no es posible excluir el resultado al actuar con el cuidado debido, entonces no puede sostenerse un vínculo causal entre la conducta y ese resultado.

De tal modo, el vínculo a reconocer tiene que ser de carácter valorativo: al respetar las medidas de precaución, el sujeto efectivamente tiene que quedar en situación de evitar la infracción de deber ${ }^{44}$. De lo contrario, la verdad de la imprudencia quedaría completamente oscurecida pues su función de aseguramiento de capacidades futura quedaría en entredicho. Este vínculo se ha denominado como conexión de contrariedad a deber o conexión de riesgo y apunta a la relación entre un hecho acaecido, el resultado no evitado y una hipótesis contrafáctica que se expresa en una frase condicional irreal ${ }^{45}$. En tal sentido, se examina lo que hubiese sucedido si el sujeto hubiese respetado el cuidado debido, puesto que si el resultado se produciría de todas formas entonces no se puede justificar la imputación a título de imprudencia. En el mismo ejemplo anterior, si la herida del sujeto se debió a que el portador del arma no verificó que estuviera descargada, entonces la conexión es fácil de establecer: parece evidente que si el tenedor hubiese cumplido la exigencia de comprobar la carga del arma, éste hubiese tenido la posibilidad de evitar el disparo lesivo ${ }^{46}$.

\footnotetext{
${ }^{43}$ Véase, por todos, ETCheBerRy (1998), pp. 320 y s. Por su parte, la jurisprudencia ha sido del mismo parecer: véase, por ejemplo, la sentencia de la Corte Suprema, rol № 7070-07, de fecha 15.09.2008: "para que nazca la responsabilidad culposa se requiere: a) que exista un comportamiento voluntario. b) que ese acto humano, acción u omisión, origine un resultado antijurídico. c) que ese resultado sea previsible. d) que exista la obligación de preverlo y e) que haya relación causal entre la acción u omisión y el resultado típico".

${ }^{44}$ En sentido similar, Rosas (2011), nota 4, a pesar de que el lenguaje utilizado ("causa", "consecuencia directa") denote más bien una tesis aún meramente causal.

45 KINDHÄUSER (1996), p. 135.

${ }^{46}$ La dificultad es que en muchos casos será extremadamente difícil afirmar, sin margen de error, la posibilidad de evitar el resultado lesivo, siendo pertinente, más bien, hablar de probabilidades, en el sentido que sería más o menos probable que el sujeto hubiese podido evitar la realización del tipo si se hubiese comportado conforme a cuidado. Y si esta conexión de contrariedad a deber es entendida
} 
Para terminar esta sección, valga una insistencia: respecto del delito imprudente no se imputa la infracción del deber de cuidado, puesto que tal infracción es simplemente el criterio (extraordinario) necesario para dar contenido a esa imputación. Hay que mantener separados conceptualmente el objeto y el criterio de la imputación. El objeto de la imputación está definido, entonces, por la norma de comportamiento precisa que apunta, en el caso de delitos de resultado, a ese resultado. En el cuasidelito de homicidio, por ejemplo, imputamos el resultado de muerte de otro a título de imprudencia; lo que ocurre igualmente en el delito doloso de homicidio en donde se imputa el resultado de muerte de otro pero ahora a título de dolo. La infracción del deber de cuidado es la razón por la cual imputamos la muerte de otro, pero no es el objeto de esa imputación ${ }^{47}$. Lo antinormativo del comportamiento, por tanto, no depende de las reglas de imputación sino que depende únicamente de la descripción típica pertinente. Sólo a través de la subsunción de normas penales se pueden diferenciar aquellas conductas que tienen interés jurídico penal de las que no lo tienen. La diferenciación entre el objeto y el criterio de imputación, por tanto, tiene que llevarnos a concluir que el injusto objetivo del delito imputado a título de dolo y el imputado a título de imprudencia es necesariamente el mismo. La variación no está en lo imputado sino en la razón por la cual se imputa ${ }^{48}$.

como necesaria para justificar la imputación del resultado, entonces no queda otra alternativa que exigir un grado de probabilidad rayana en la certeza sobre la posibilidad de evitación del accidente. O sea, si no existe suficiente certeza sobre la efectiva posibilidad de evitación, entonces no será posible responsabilizar al sujeto involucrado en el accidente. Y los sectores que presentan dificultades para fundar esta conexión son precisamente aquellos regulados por normas del tráfico que pretenden determinar una manera correcta de desempeñarse en la actividad debido al altísimo riesgo de que una acción degenere en una realización típica. En este ámbito es donde un bien entendido concepto de riesgo permitido puede entregar ciertas luces sobre la forma en la que debieran resolverse estos casos complejos. Véase, infra, pp. 16-17.

47 Mediante la diferencia conceptual entre objeto y criterio de imputación es posible resolver uno de los problemas recurrentes de la jurisprudencia y doctrina nacional: "el cuasidelito con resultado múltiple", es decir, el comportamiento negligente que provoca varios resultado lesivos similares y que es de normal ocurrencia en accidentes vehiculares. Así, se puede concluir que la configuración del resultado pertenece al análisis de la antinormatividad, puesto que ella atiende a la descripción típica y, por tanto, a los elementos que el legislador ha tenido en consideración para que un hecho tenga relevancia penal. De tal forma, está relacionado con el objeto y no con el criterio de la imputación. En otras palabras, la multiplicidad de resultados no tiene conexión con la imprudencia (o con el dolo) sino con un hecho que debe subsumirse en el tipo penal. De ahí que, por ejemplo, quien negligentemente provoca la muerte de dos personas hace valer la norma que prohíbe el homicidio, la cual otorga relevancia a la cantidad de resultados producidos, verificándose dos cuasidelitos de homicidio (y no un cuasidelito con resultado de dos muertes). Para una revisión detallada de la jurisprudencia asociada al problema, véase EtCheBerRy (2002), Tomo I, pp. 262 ss. y Tomo IV, pp. 263 y ss.

48 En el mismo sentido, véase Pérez Del Valle (2012), pp. 77 y ss., 107 y ss. En contra, véase Corcor (1989), pp. 90 y ss., para quien el deber de cuidado ya reclama relevancia en el ámbito del injusto objetivo, puesto que reconoce que existe una norma específica que se refiere al delito doloso y otra 


\section{El riesgo permitido como consecuencia de exigencias de cuidado razonables}

La tesis respecto del riesgo permitido a fundamentar en lo que sigue reza: el riesgo permitido tiene que entenderse como la tolerancia del ordenamiento a la limitación de la capacidad de acción basado en el presupuesto que no es posible prevenir todo riesgo. Como no es posible evitar todo riesgo, entonces las exigencias de cuidado se estructuran como incumbencias razonables ${ }^{49}$ que siempre implican un riesgo residual de resultado lesivo pero carente de responsabilidad. Lo relevante está, por tanto, en que la noción de riesgo permitido sólo puede concebirse en virtud del sistema de imputación a título de imprudencia, estando completamente fuera de lugar su alegato en el ámbito de los delitos dolosos. De tal modo, el riesgo permitido explicita el límite de la responsabilidad penal: si aun cumpliendo las exigencias de cuidado se genera un menoscabo para el bien jurídico, entonces no hay buenas razones para atribuirle el resultado a alguien, lo que conlleva el fracaso del proceso de imputación y la exclusión del injusto subjetivo.

Así entonces, la dogmática del delito imprudente no pretende imponer estándares que reduzcan todo riesgo de accidente. Porque reducir la probabilidad de resultado típico a cero, o sea, asegurar su no ocurrencia, implicaría la asunción de medidas excesivas que limitarían la ejecución beneficiosa de la actividad, puesto que muchas veces lo adecuado para evitar todo riesgo será simplemente la no ejecución de la acción. A modo de ejemplo, como aquel sujeto avezado en la conducción motorizada no puede asegurar que no producirá un accidente, entonces tendría que serle exigible la no conducción. Y como esta conclusión no es sensata, pues toda actividad social útil conlleva un riesgo de resultado lesivo, entonces incluso la actuación cuidadosa implica la asunción de un mínimo de riesgo. Por tanto, en los casos en que el derecho penal establece normas explícitas de cuidado de una determinada actividad (por ejemplo, la ley del tránsito) entonces está "permitiendo" un margen de riesgo, es decir, está estableciendo un determinado estándar de conducta cuidadoso que le indica al partícipe la forma correcta de comportarse. Pero, aún más importante, se establece el límite superior exigible ya que existiendo mayores y mejores medidas de precaución se entienden como suficientes, jurídico penalmente hablando, aquellas que señala la norma. Superiores medidas de cuidado son, entonces, supererogatorias. Si la ley del tránsito fija en $120 \mathrm{~km} / \mathrm{h}$ la velocidad máxima en

norma que se refiere al delito imprudente. Esta duplicidad normativa es totalmente incompatible con el reconocimiento del dolo como un criterio de imputación convirtiéndose más bien en un elemento típico.

49 Respecto a la configuración de la exigencia de cuidado como una incumbencia, véase KINDHÄUSER (2013), pp. 225. 
carretera, ello implica un riesgo porcentual de accidente (tanto evitable como inevitable) de X\%; ahora, si un conductor maneja a $100 \mathrm{~km} / \mathrm{h}$ en carretera, el riesgo de accidente se verá disminuido a $X-1 \%$, porque por ejemplo la distancia de frenado será menor y por tanto una porción de eventuales accidentes se verán evitados. Lo relevante es que el ordenamiento permite la creación de riesgo correspondiente a $\mathrm{X} \%$ puesto que ha fijado una determinada velocidad máxima, siendo inexigible una velocidad inferior aun cuando ésta hubiese sido necesaria para impedir un accidente.

Lo que ocurre es que, con el establecimiento de medidas de precaución, el ordenamiento está tolerando, dentro de ciertos límites, una reducción de la propia capacidad de seguimiento de la norma ${ }^{50}$, pues el sujeto será incapaz de evitar resultados lesivos que hubiesen requerido un superior nivel de cuidado. Y si precisamente por esa incapacidad se originase responsabilidad penal, entonces no podríamos sino afirmar una esquizofrenia jurídica: por una parte, se permite la disminución de la capacidad de acción, y por otra se sanciona por esa misma disminución de capacidad. En tal sentido, en los casos en que el accidente se produce precisamente por esa acción supererogatoria, se puede hablar de la realización de un riesgo permitido ${ }^{51}$. Por tanto, con las normas explícitas de cuidado, el ordenamiento jurídico no solamente establece criterios para la determinación del cuidado debido, sino que al mismo tiempo excluye la posibilidad de reclamar responsabilidad por el riesgo residual: no es posible achacar al autor su incapacidad para evitar la acción como contraria al deber de cuidado $^{52}$. Así, como el derecho permite una velocidad máxima de $120 \mathrm{~km} / \mathrm{h}$, entonces el riesgo que igualmente se genera al conducir a esa velocidad y que genera un accidente, debe ser entendido como riesgo permitido.

En los ámbitos en que existen normas explícitas de cuidado, el riesgo permitido se observa con claridad. Ya que cuando el sujeto actúa respetando esas normas igualmente subsiste un riesgo de resultado típico que el mismo ordenamiento permite porque no es posible exigir su total disminución. Por ejemplo, el conductor prudente o el médico cuidadoso igualmente generan riesgos pero que están permitidos dado el cumplimiento de la normativa respectiva. No obstante, en aquellas áreas donde no existe una reglamentación específica del adecuado desempeño de una actividad, también se puede apreciar un riesgo permitido pues éste se relaciona con el cumplimiento de las exigencias de cuidado, sin

\footnotetext{
50 KINDHÄUSER (2013), p. 226.

51 KINDHÄUSER (2007), p. 65.

52 KINDHÄUSER (1996), p. 128, quien también señala que "la incapacidad para evitar la realización del tipo penal en el momento decisivamente relevante es insignificante cuando ella es la consecuencia necesaria de la observación de un permiso".
} 
importar la forma en que ellas se determinen. Por ejemplo, supongamos que un atleta olímpico A está entrenando en una pista dentro de una plaza de acceso público, de modo varias personas circulan por el rededor. Como no existen una regulación -ni normativa ni consuetudinaria- respecto del entrenamiento en plazas públicas, A debe actuar conforme a cuidado en atención al contexto en que se desempeña, por ejemplo, no puede correr demasiado rápido porque hay niños jugando en las cercanías. Supongamos ahora que A cumple con todas las precauciones que un destinatario fiel a derecho tomaría, pero aun así durante un ejercicio de elongación golpea a un niño que se acercaba sigilosamente siendo completamente imposible notar su presencia. ¿Debe responder A por un cuasidelito de lesiones? No, porque a pesar de que el resultado típico se vincula causalmente con una acción de A, éste se comportó conforme a cuidado, de manera que el riesgo que subsiste es sólo riesgo permitido.

Y, por tanto, entendiendo al riesgo permitido como un riesgo residual que no puede excluirse aun empleando el cuidado debido, éste se muestra como la otra cara de la infracción de cuidado ${ }^{53}$. Así, quien crea un peligro jurídicamente permitido siempre actúa conforme a cuidado, puesto que el criterio relevante para determinar el riesgo permitido está dado por el estándar de cuidado respectivo. En otras palabras, la observancia de las exigencias de cuidado tiene un efecto de exoneración porque, aun cuando de la acción se derive un resultado típico, no puede imputarse responsabilidad imprudente ya que nadie está en posición de evitar, en todo momento, las consecuencias lesivas de su comportamiento ${ }^{54}$.

Ahora bien, es en la determinación de las exigencias de cuidado y, por tanto, del margen de riesgo permitido donde reclama relevancia el rol social que ejerce el agente. Porque la posición que el sujeto desempeña repercute en las expectativas de cuidado que recaen a su respecto, influyendo directamente en las medidas que tienen que ser seguidas para asegurar su capacidad de evitación futura. De ahí que el rol tenga impacto en la fijación del riesgo permitido, porque usualmente los roles exigen ciertas habilidades o conocimientos que facultan su desempeño: para quien carece de tales mínimos, lo cuidadosamente debido será simplemente que omita la actividad. En cambio, el sujeto que cumple con esas habilidades y participa de la actividad tomando las precauciones correspondientes igualmente genera un margen de riesgo. Los daños que se

\footnotetext{
${ }^{53}$ Kindhäuser (2007), p. 65. En un sentido similar, Pérez del Valle (2012), pp. 120 y s., quien señala "sea cuál sea la posición sistemática que se atribuya al riesgo permitido, no existe una discrepancia esencial entre su contenido y el propio de la infracción del deber de cuidado".

54 KindhäUser (2013), p. 226. En el mismo sentido, Ovalle (2011), p. 6 quien, a pesar de ciertas confusiones -explicitadas en supra, n. 19- termina evidenciando la relación entre el riesgo permitido y la imprudencia. La relación entre el riesgo permitido y la imprudencia incluso es observada por JAKOBS (1995), pp. 245 y s.
} 
produzcan por una incapacidad del sujeto que excede al cuidado exigido por el rol pueden reconducirse, entonces, al ámbito del riesgo permitido ${ }^{55}$. De modo que si ese resultado típico se produce debido a la insuficiencia de habilidades, con todo, superiores a las exigidas por el rol social desempeñado, existe una tolerancia normativa de su causación. Es decir, la obtención de capacidades superiores, incluso cuando existe certeza que hubiesen permitido la evitación del resultado lesivo, son supererogatorias puesto que esa relativa incapacidad de acción del agente está permitida de acuerdo a las expectativas normativas que determinan el estándar de cuidado a considerar.

Téngase presente que la referencia a los roles sociales no puede contar como una cierta aceptación de la teoría de la imputación objetiva. Porque aquí sólo nos interesa el rol como elemento relevante para la determinación de la exigencia de cuidado en un contexto específico. Así, el concepto principal sigue siendo la exigencia de cuidado y el rol es simplemente un insumo que permite concretarla adecuadamente. Por el contrario, para una teoría de la imputación objetiva, el rol es el concepto principal y, dentro de su ámbito de influencia, se pretende aplicar los conceptos de dolo e imprudencia.

De quien se desenvuelve en un cierto rol se espera, entonces, un cierto grado de expertise mínimo y un comportamiento cuidadoso en la actividad que, en definitiva, establecen un nivel de capacidad de acción específico puesto que el sujeto podrá evitar ordinariamente ponerse en situación de inevitabilidad. Sin embargo, como no se exige una reducción de los riesgos a cero, entonces ese nivel de capacidad de acción sienta también un nivel de incapacidad de acción para situaciones excepcionales en las cuales no podrá controlar su capacidad futura, y que tendrán que ser toleradas. El ordenamiento no puede desconocer que al establecer un estándar de cuidado está tolerando la causación de resultados típicos derivados de la prescindencia de una precaución superior a la exigida. Independiente que esa precaución superior consista en, por ejemplo, una adquisición de mayores conocimientos que los exigidos según el rol o en la ejecución de una conducta no exigible en atención a la posición del agente, ella no puede fundar responsabilidad.

Lo relevante es que el riesgo permitido encierra una conexión inmediata con las exigencias de cuidado respectivas, ya que es necesario tener a la vista el estándar para establecer lo que queda por sobre él. De tal modo, el concepto de riesgo permitido es secundario frente a la imputación a título de imprudencia, pues el riesgo que el ordenamiento está dispuesto a tolerar depende de cuáles son las medidas de precaución exigibles en un determinado contexto para evitar un inevitable resultado lesivo. Cuando hablamos abstractamente del riesgo

55 KindHÄUSER (2008), p. 23. 
permitido, estamos suponiendo un determinado nivel de cuidado que asegura la capacidad de seguimiento posterior, pero en donde persiste una diferencia de riesgo que puede conducir a un resultado típico sin generar responsabilidad en el autor. De ahí que resulte incorrecto postular al riesgo permitido como un concepto autónomo que puede excluir, desde fuera, la imputación a título imprudente e, incluso, a título dolosa. El riesgo permitido no es más que el reconocimiento que el proceso de determinación del estándar de cuidado lleva consigo la tolerancia de riesgos no abarcados por éste.

En todo caso, en ámbitos donde existen normas explícitas de cuidado que facilitan la observancia del riesgo permitido es donde la comprobación de la conexión de contrariedad a deber se hace especialmente compleja ${ }^{56}$. Porque ello implica que el mismo ordenamiento entrega una permisión de cierta incapacidad de acción que tiene que ser considerada al momento de verificar esta conexión. Ya señalábamos que tal conexión consiste en la posibilidad de afirmar que si el sujeto se hubiese comportado conforme a cuidado, esto es, respetando las reglas pertinentes, hubiese podido evitar el resultado típico. Pero en estos ámbitos regulados se hace especialmente difícil sostener con toda certeza la evitación de ese resultado. Y dado que existen normas precisas para controlar los riesgos, que implican automáticamente un riesgo permitido en el exceso, es necesario comprobar que la falta de evitabilidad del accidente justamente se base en haber sobrepasado el margen de riesgo permitido ${ }^{57}$. Como usualmente sólo podremos hablar de probabilidades en la evitación del hecho por parte del autor, entonces es necesario sentar un criterio. Por ejemplo, si se produce un atropello y el conductor manejaba a $150 \mathrm{~km} / \mathrm{h}$, es necesario afirmar que si hubiese conducido a la velocidad máxima legal $(60 \mathrm{~km} / \mathrm{h})$, y por tanto en el marco del riesgo permitido, hubiese sido posible la evitación del accidente. Entonces, para resolver el problema, lo sensato sería que mientras subsistan dudas procesalmente relevantes sobre la evitabilidad de la realización del tipo con base en el cumplimiento del riesgo permitido, no será posible la imputación ${ }^{58}$. En otras palabras, mientras no se pueda afirmar con un grado de probabilidad rayana en la certeza que el conductor hubiese podido evitar el atropello conduciendo a $60 \mathrm{~km} / \mathrm{h}$, entonces no hay imprudencia pues sólo allí podemos estar seguros que el accidente no se debe a un riesgo permitido, o sea, a una incapacidad de acción tolerada por el ordenamiento.

En definitiva, el riesgo permitido es una manifestación de que resulta sumamente poco razonable $-y$, por lo demás, impracticable- exigir la evitación, a

56 Supra, p. 12.

57 KINDHÄUSER (2013), p. 227.

58 KINDHÄUSER (1996), p. 136. 
todo evento, de resultados típicos. Al reconocer esta dificultad, se entiende que sólo es posible responsabilizar a quien estuvo en posición de seguir la norma, lo cual queda recogido en el principio ultra posse nemo obligatur. Asumir este principio trae consigo el establecimiento de una frontera en el conjunto de resultados lesivos, esto es, hechos socialmente dañosos. Hasta esa frontera se encontrarán todos aquellos hechos que pueden ser evitados, es decir, que pueden ser imputados a título de dolo o imprudencia. Más allá del límite, quedan aquellos hechos que, aunque vinculados causalmente a la acción de un sujeto, no pueden ser imputados pues era imposible su evitación. El riesgo permitido explicita la función de esa frontera: si el resultado no hubiese podido ser evitado por un agente que actúa conforme a los estándares de cuidado respectivos, entonces no puede haber responsabilidad ${ }^{59}$. Se trata, por ende, de una pérdida social que tiene que ser tolerada para mantener la relación entre el derecho penal y las capacidades de seguimiento de esas normas por la sociedad. Por eso, no es tanto que el riesgo se permita -riesgo permitido- sino más bien que el riesgo se tolera -riesgo tolerado- con el objeto de mantener el principio ultra posse nemo obligatur como medular en la imposición de una pena. Renunciar al riesgo permitido como expresión del límite implicaría la aceptación, en algunos casos, de una responsabilidad penal objetiva basada únicamente en el reconocimiento de hechos desfavorables.

\section{Precisando la noción de riesgo permitido}

a) En esta sección, se tratarán tres cuestiones que desarrollan el correcto entendimiento del riesgo permitido: son conclusiones de la presentación ya realizada, pero que ahora se harán explícitas y tratadas con mayor profundidad.

En primer lugar, el riesgo permitido está relacionado con el tipo subjetivo, no con el objetivo. La teoría de la imputación objetiva considera al riesgo permitido como uno de los elementos estructurales del injusto objetivo, en el sentido que opera como criterio previo a la consideración del autor concreto. Lo que estaría permitido, como vimos, se determina objetivamente atendiendo a un observador abstracto que distingue entre la creación de peligro jurídicamente relevante, eventualmente meritorio de pena, y la de peligro irrelevante, por encontrarse en el margen permitido. En tal sentido, el riesgo permitido excluiría ya el disvalor de resultado, en el sentido que está permitido realizar esa conducta por el beneficio social que de ella se deriva y que se observa mediante una ponderación de intereses.

Sin embargo, el riesgo permitido nada tiene que ver con la manera en la cual se exterioriza la acción como resultado que satisface una descripción típica,

59 KindHÄUSER (2008), p. 23. 
sino con la capacidad del autor de evitar conforme a cuidado una situación de inevitabilidad de infracción del deber. O sea, el riesgo permitido excluye únicamente el injusto de la acción ${ }^{60}$, pues afirmar que alguien actúa en el margen permitido sólo puede significar que aun cumpliendo las exigencias del cuidado la producción del resultado lesivo resulta inevitable. No existe, por tanto, ni la infracción del deber de acción propia de la imputación dolosa ni la infracción de la incumbencia propia de la imputación a título de imprudencia, siendo imposible la responsabilidad penal.

En el riesgo permitido, es el mismo ordenamiento quien permite una cierta incapacidad de acción, ya sea específicamente con normas explícitas de cuidado o genéricamente con la exigencia de cuidado, en la cual el sujeto no podrá evitar el hecho típico, pero no deberá responder por ello porque esa incapacidad está tolerada. Lo relevante es que esa incapacidad no evidencia una carencia de la voluntad para cumplir con la norma, esto es, no existe déficit en la fidelidad al derecho ${ }^{61}$. Quien actúa bajo el riesgo permitido, hizo lo posible en asegurar su capacidad de seguimiento a través del respeto de las medidas de precaución pertinentes, pero el resultado igualmente se concreta producto de un peligro suyo, el cual no expresa una negación del derecho dado que no existe demérito alguno en la forma de comportarse del autor: no-poder tiene que implicar no-deber. El injusto de resultado no ha desaparecido, sino que simplemente no puede serle imputado a sujeto alguno.

b) En segundo lugar, el riesgo permitido no puede entenderse como una causa de justificación. Las causas de justificación son normas de permisión para realizar una conducta que, en otras circunstancias, estaría prohibida. Es decir, una misma conducta satisface la descripción de una norma prohibitiva y la de una norma permisiva, en la cual la permisión primará, siendo desplazada la prohibición ${ }^{62}$. Por tanto, una causa de justificación cuenta como una exclusión del injusto (antijuridicidad) del comportamiento prima facie prohibido. La legítima defensa es el caso más evidente: si A mata a B concurriendo condiciones suficientes de defensa, entonces A infringe la prohibición del homicidio y, al mismo tiempo, ejecuta la permisión de matar a alguien en situación de legítima defensa. El ordenamiento reconoce, entonces, que aun configurado adecuadamente el tipo objetivo del homicidio, puesto que existe un resultado antinormativo consistente en la muerte de B por A, y el tipo subjetivo, porque la muerte de B es imputada dolosamente a A, ello queda "derrotado" por la

60 KINDHÄUSER (2007), p. 66.

61 KINDHÄUSER (1996), p. 129.

${ }^{62}$ Sobre la discusión referente a si las normas de permisión confieren derechos subjetivos para la ejecución de la acción defensiva, véase a favor Silva Sánchez (2013). Véase, en contra, Mañalich (2013). 
también adecuada satisfacción de la legítima defensa. No es que, en realidad, no exista tipicidad del homicidio, sino que la satisfacción de las condiciones del permiso desplazan la prohibición.

Ahora bien, el riesgo permitido carece de las características propias de cualquier causa de justificación. El riesgo permitido tiene que ver con la expectativa en el autor que no reducirá su capacidad de acción de una forma contraria a la exigencia de cuidado ${ }^{63}$. Es una tolerancia normativa a la producción de ciertos riesgos que escapan al control por cuidado y, por tanto, tolerancia a que el sujeto estará incapacitado de evitar en todo caso situaciones de inevitabilidad en la infracción del deber. En tal sentido, el riesgo permitido no se opone ni excluye la prohibición, como sí lo hace una causa de justificación, sino que el resultado no puede ser imputado al autor porque actuó en un margen tolerado de incapacidad. Asimismo, quien conduce dentro de la velocidad máxima no tiene una autorización para lesionar a un peatón que interviene en el tráfico, de forma que ante un accidente contra el peatón igualmente subsiste el injusto objetivo $^{64}$. Es decir, el resultado antinormativo existe y persiste. En cambio, respecto de las causas de justificación, y cumpliéndose sus requisitos, sí existe una autorización para causar un resultado típico. En el caso de conducción vehicular, lo único que sucede es que el ordenamiento tolera la reducción de la capacidad de acción dentro de los márgenes de la velocidad permitida, de modo que no existe injusto subjetivo: no es posible imputar el resultado al conductor porque para el sujeto, en el marco entregado por el ordenamiento, era inevitable su comisión.

No existe una categoría de riesgo permitido, entonces, que excluya la antijuricidad de la conducta prevaleciendo sobre la prohibición, sino que el comportamiento del sujeto simplemente no es antijurídico porque no se satisface la imputación extraordinaria: no hay una actuación contraria a cuidado que desencadena un resultado típico sino una actuación riesgosa permitida en vista de los límites de la capacidad del sujeto y las exigencias normativas a su conducta. De ahí que puede ser importante modificar el término de riesgo permitido a riesgo tolerado. Riesgo permitido puede llevar a una confusión terminológica, al entender el "permitido" en un sentido fuerte, es decir, como el resultado de una aplicación de una norma de permisión. La tolerancia, por el otro lado, expresa precisamente el reconocimiento normativo de márgenes de peligro aceptados.

63 KINDHÄUSER (1996), p. 130.

${ }^{64}$ KindHÄUSER (2007), p. 66. En KindHÄUSER (2013), p. 226 se plantea que "las reglas del tráfico vehicular no conceden una autorización para lesionar, o incluso matar, a otros. Ellas sólo excluyen la imputación de una lesión corporal o un homicidio no doloso como infracción de deber imprudente". 
c) $Y$ en tercer lugar, el riesgo permitido no es pertinente para excluir la imputación a título de dolo. El dolo evidencia la capacidad cognitiva del sujeto para evitar una acción que cuenta como infracción de deber, es decir, que el autor posee el conocimiento de que su conducta causará con una probabilidad suficiente un resultado típico. Si el conductor, por ejemplo, atropella a un peatón que observó con suficiente anticipación cruzando la calle por un lugar indebido, pero que estaba en condición de evitar sólo disminuyendo levemente la velocidad, no puede reclamar impunidad con base en riesgo permitido ya que estaba suficientemente capacitado tanto física como cognitivamente para evitar el resultado típico, de tal forma que su actuar es doloso ${ }^{65}$.

El riesgo permitido excluye responsabilidad debido a una incapacidad tolerada del sujeto en la evitación del resultado lesivo: el ordenamiento acepta que el sujeto en determinadas situaciones no pueda asegurar su capacidad de seguimiento futura. Sin embargo, si el sujeto conoce las circunstancias de su acción en el sentido que con seguridad infringirá su deber de evitar la infracción de cierta norma de comportamiento, entonces evidentemente está capacitado para evitar ese resultado: no se presenta ninguna incapacidad a la que el riesgo permitido pueda estar referida. En cambio, la posibilidad del delito imprudente implica, desde ya, que el autor carece de esa capacidad siendo posible únicamente una imputación extraordinaria ante la infracción de exigencias de cuidado que provocan la inevitabilidad de la infracción de deber. Por tanto, el riesgo permitido está referido no a la evitación, conforme a deber, de un comportamiento prohibido, sino a la evitación, conforme a cuidado, de la incapacidad de seguimiento, conforme a deber, de una prohibición ${ }^{66}$.

De tal forma, cada vez que examinamos la posibilidad de ejecución dolosa del comportamiento la referencia al riesgo permitido queda descartada ${ }^{67}$, simplemente porque aluden a diferentes niveles lógicos de imputación. De la misma forma que no tiene sentido discutir sobre las exigencias de cuidado en los casos de comisión dolosa, tampoco tiene sentido la referencia al riesgo permitido. La teoría de la imputación objetiva, entonces, se equivoca puesto que en su afán de introducir una imputación ya en el injusto objetivo referido a un observador abstracto, entiende al riesgo permitido como una ponderación, de nuevo, abstracta de intereses, en donde no interesa todavía la capacidad del autor concreto: lo permitido se determina según lo que socialmente resulte beneficioso. Sin embargo, sin desmerecer el análisis sociológico, aquello no puede ser el único argumento que justifique la impunidad penal. La responsabilidad penal tiene

65 KINDHÄUSER (2007), p. 67.

${ }^{66}$ KINDHÄUSER (2013), p. 225.

67 KINDHÄUSER (1996), p. 137. 
que relacionarse con lo que puede hacer un sujeto en un momento determinado y lo que estaba obligado a hacer en atención a las normas que regulan ámbitos de nuestro comportamiento. Que, en abstracto, resulte socialmente beneficioso, o que es lo mismo, beneficioso para ciudadanos promedio genéricos, no puede servir de argumento para imponer o excluir responsabilidad a un sujeto específico: su responsabilidad sólo depende de lo que estaba obligado a hacer y de lo que podía hacer para cumplir con su deber ${ }^{68}$.

La única forma en que una imputación dolosa exitosa puede decaer es cuando el mismo ordenamiento entrega una permisión de realización de esa conducta dolosa, en la forma de una causa de justificación. Pero ya afirmamos que el riesgo permitido no asume esta función. Así, sólo existe una relación lógica posible entre el riesgo permitido y el dolo: incompatibilidad.

\section{Sobre el principio de confianza}

Respecto de la relevancia de las acciones de otros sujetos para la eventual antijuridicidad del comportamiento propio, la teoría de la imputación objetiva acude a la noción de principio de confianza ${ }^{69}$. Éste plantea, en términos simples, que quien se comporta debidamente puede confiar en que otros también lo hagan. Porque si mantuviéramos una actitud escéptica respecto de la conducta de los demás, en el sentido de establecer medidas de cuidado ante su posible conducción imprudente, no sería posible la realización de actividad alguna, puesto que lo cuidadoso sería precisamente la abstención de esa $\operatorname{actividad}^{70}$. De tal forma, si el sujeto estaba autorizado a confiar y su acción igualmente genera un riesgo que termina realizándose en un resultado lesivo, estaría excluido el injusto al no prosperar la imputación objetiva al tipo.

El principio de confianza opera, entonces, como el fundamento normativo de la actuación múltiple con división del trabajo, principalmente en ámbitos industriales y médicos ${ }^{71}$. De lo contrario, cada participante tendría que asegurarse

68 KINDHÄUSER (2008), p. 30, quien afirma, en un tema algo diferente pero igualmente relacionado (cursos causales inadecuados), que "el derecho penal no se trata del juzgamiento del curso del mundo, sino sólo de la pregunta de si una persona ha de hacerse cargo de la producción de un determinado daño por el hecho de que ella hubiese podido y tenido que evitarlo bajo el motivo dominante de seguir la norma".

${ }^{69}$ También sobre la eventual importancia de los comportamientos ajenos trata el concepto de prohibición de regreso, pero orientado más bien -en el seno de la teoría de la imputación objetiva- a la determinación de roles sociales que definirían los deberes penales individuales. Véase JAKOBS, DPPG, pp. 229 y s. y JАKOBS, La imputación objetiva, p. 216.

70 JаKOBS (1997b), p. 219.

${ }^{71}$ Confróntese, Rosas (2011), pp. 6 y ss., quien distingue el principio de confianza del principio de división del trabajo, aunque evidencia la íntima relación entre ambos. 
del trabajo correcto de los demás miembros, lo que se opondría a la finalidad misma de dividir el trabajo.

Ahora bien, sobre la fundamentación del principio de confianza, existe bastante acuerdo en que éste sería un caso de aplicación del riesgo permitido ${ }^{72}$ : el riesgo de un resultado lesivo por un comportamiento de otro está permitido en atención a las ventajas individuales y sociales que la confianza ofrece ${ }^{73}$. De ahí que lo decisivo estaría en trazar correctamente los límites del principio de confianza, determinando con claridad cuándo ya no se puede confiar en el comportamiento correcto ajeno; es decir, cuándo la acción creadora de riesgo ya defrauda expectativas normativas de conducta, mereciendo reproche penal.

Así, el principio de confianza operaría siempre y cuando el autor no tenga deberes especiales de supervisión sobre la conducta de otros ${ }^{74}$. En este caso, la actividad consiste en compensar y prevenir los fallos de otros, de modo que no está autorizado a confiar simplemente en su no ocurrencia ${ }^{75}$. El cirujano jefe a cargo de una intervención quirúrgica, por ejemplo, debe vigilar la actividad de los demás cirujanos, de modo que si ocurre un accidente por falla de uno de ellos, el cirujano jefe no podrá defenderse en virtud del principio de confianza si no cumplió adecuadamente sus deberes de control, configurándose negligencia médica a su respecto ya que infringe las exigencias de cuidado que, en su caso, consistían en vigilar el trabajo de los otros.

\footnotetext{
72 Véase Roxin (1997), p. 1006; Corcoy (1989), p. 328. En contra, Rosas (2011), p. 9, quien reconoce la posición mayoritaria pero asume que el fundamento del principio de confianza se encontraría en el "principio de autorresponsabilidad", ya que al sujeto que confía "no puede hacérsele responsable de la infracción del deber de cuidado que corresponde al ámbito de responsabilidad de otro sujeto responsable".

${ }^{73}$ Sin embargo, además del riesgo permitido, el principio de confianza estaría íntimamente conectado con la prohibición de regreso porque tiene que ver con la intervención de extraños al curso causal potencialmente lesivo. Esto ha llevado a que Jakobs entienda el principio de confianza como una fusión entre el riesgo permitido y la prohibición de regreso (JAKOBS (1995), p. 254: "mientras que en el riesgo permitido cabe definir un conflicto como fallo del autor, o de la víctima, o como desgracia, en la prohibición de regreso se añade la posibilidad de definir el conflicto como fallo del tercero interviniente; esta posibilidad de trata un conflicto podría formar la raíz principal del principio de confianza") y que Roxin lo comprenda como una reformulación de la antigua prohibición de regreso (Roxin (1997), p. 1007: "aquí (en el principio de confianza) radica el núcleo correcto de la antigua teoría de la prohibición de regreso, aún defendida en la actualidad con distintas fundamentaciones, según la cual la cooperación no dolosa en delitos dolosos es impune").

74 JаKOBS (1997a), p. 177.

${ }^{75}$ Para Corcor (1989), pp. 329 y s., el principio de confianza no sólo se vería limitado en casos de deberes de supervisión sino en caso de infracción de cualquier deber de cuidado. El problema es que tal solución confunde la pregunta relevante: lo que se está analizando es si la confianza en los demás implica, en determinados casos (y en qué casos), una infracción de exigencias de cuidado, de modo que si se dice que la infracción de la exigencia de cuidado conlleva la negación del principio de confianza, entonces no se está diciendo nada que responda la interrogante inicial.
} 
Por otro lado, el principio tampoco es aplicable cuando la confianza en el comportamiento de otros está injustificada, o sea, respecto de personas que carecen de la capacidad necesaria para fundar la confianza de conducta de acuerdo a la norma, ya sea por su desarrollo intelectual o por el contexto en el que se encuentran ${ }^{76}$. Esto es lo que usualmente se conoce como principio de defensa ${ }^{77}$. De esta forma, quien conduce un vehículo no puede confiar en que los niños que juegan en el parque no corran hacia la calle en busca de una pelota, de manera que deberá tomar las medidas de precaución pertinentes (probablemente disminuir la velocidad). Pero tampoco podrá confiar el conductor que transita por el interior de un carnaval multitudinario en que los asistentes no ocupen la calle repentinamente para desplazarse.

De acuerdo a lo anterior, el límite último del principio de confianza está en la ocurrencia de la conducta defraudadora de expectativas ${ }^{78}$. No es posible seguir confiando en que otro se comportase adecuadamente si actualmente ya se comportó contrario a lo que se esperaba. Lo anterior es baladí por evidente, pero de ello se deriva lo siguiente: si existen indicios suficientes del no seguimiento futuro de la norma por otro, entonces tampoco estaría permitido confiar. El cirujano jefe, continuando el ejemplo, que observa que otro de los cirujanos no puede mantenerse concentrado en la intervención quirúrgica debido a alguna enfermedad, no puede seguir confiando y debe poner en práctica las medidas de precaución necesarias para evitar alguna lesión.

De tal forma, el principio de confianza se vería descartado toda vez que existan indicios suficientes de que se cometerá un delito posterior ${ }^{79}$. No estarían dadas las condiciones para que la confianza esté justificada, debiendo recurrirse al sistema general del delito para determinar la responsabilidad penal del agente. Otro ejemplo: quien entrega un cuchillo a un sujeto que está luchando con otro no puede confiar justificadamente en que el peleador no lo utilice, de modo que se hace responsable al menos por participación imprudente si llegase a ocurrir la muerte del adversario. Porque excluida la confianza se debe practicar el ya familiar proceso de imputación: descartada la imputación por falta de dolo, queda la extraordinaria por imprudencia, en donde se concluiría la infracción de la exigencia de cuidado en la entrega del cuchillo bajo esas condiciones.

En definitiva, someter la eficacia del principio de confianza a la inexistencia de indicios de comisión delictiva posterior obliga una preocupación del

\footnotetext{
${ }^{76}$ JаковS (1997b), р. 219.

77 Corcor (1989), pp. 331 y ss.

${ }^{78}$ JаковS (1997b), p. 220. Para una revisión detallada de las concreciones del principio de confianza en el ámbito médico, véase Rosas (2011), pp. 7 y ss.

79 Roxin (1997), p. 1007.
} 
autor en la verificación de las circunstancias de la acción con el objeto de ser capaz de atender a aquellos indicios. Esto termina limitando ampliamente el efecto pretendido por los defensores de la imputación objetiva ${ }^{80}$, cual es, particularmente la despreocupación por la actuación de los demás. Pues si bien la fundamentación inicial de la confianza no parece generar demasiadas dudas, porque nadie estaría dispuesto a exigir medidas de cuidado frente al posible comportamiento incorrecto ajeno, la necesaria configuración conceptual del principio ofrece numerosas dificultades que atentan contra el contenido del mismo. Dado que, en realidad, no puedo confiar de inmediato en el comportamiento ajeno ya que debo evaluar el contexto de actuación para determinar, en definitiva, si es razonable confiar, ¿entonces cómo podríamos diferenciar el principio de confianza con el ámbito general de la imputación a título de imprudencia, en el sentido que también aquí se exigen medidas de precaución para un actuar razonable?

Y para una posición que entienda al riesgo permitido como un concepto propio del ámbito de imputación a título de imprudencia, como la sostenida aquí, la respuesta tiene que evidenciar que la confianza en el actuar de otros no depende de los roles objetivos que éstos desempeñan sino de la posibilidad de relacionar adscriptivamente la conducta de los demás a la propia. Es decir, en atención a las sensatas limitaciones que los mismos partidarios de la imputación objetiva entregan, el desafío está en determinar si existe algún ámbito en que no resulte exigible verificar si la confianza en otros está justificada.

En atención a ello, es importante tener presente que las exigencias de cuidado también pueden estar referidas a la conducta de otro, es decir, tendrá que tomarse en cuenta la conducta de otro para determinar si el comportamiento fue o no cuidadoso. Utilizando los mismos ejemplos previos: a quien conduce cerca de un parque donde juegan niños pequeños se le exige mayor cuidado respecto de quien no lo hace, debiendo aminorar la velocidad. Incluso en casos extremos, puede no ser prudente (cuidadoso) emprender una determinada acción en vista del comportamiento que puedan asumir otros sujetos, puesto que no se podría asegurar la capacidad para evitar posteriormente una participación delictiva. Eso es lo que ocurre en el caso de entrega sin dolo de un cuchillo a un sujeto en medio de una pelea con otro.

En tal sentido, la posibilidad de confiar en la conducta de los demás no se sostiene en un principio objetivo externo sino simplemente en si resulta sensata, dadas las circunstancias, esa confianza. Cuando deja de ser razonable confiar, porque la conducta del otro no justifica esa confianza, entonces deberán tomarse

${ }^{80}$ Y esto con independencia de lo problemático que resulta ser atender a la información conocida por el autor en un criterio que pretende ser puramente objetivo. 
las medidas de precaución necesarias para evitar el resultado típico. Así, el médico confía en su equipo mientras sea razonable hacerlo porque, por ejemplo, todos son calificados y expertos en la materia; pero si interviene un médico principiante, la confianza se ve disminuida puesto que tendrá que tomar las precauciones necesarias para evitar un desenlace fatal. Y esta sería, entonces, la explicación de las restricciones al principio de confianza por la teoría de la imputación objetiva, la cual reconoce las dificultades de una confianza a todo efecto y termina sosteniendo una tesis más bien moderada (y similar a la aquí desarrollada).

¿Entonces no existe ningún ámbito donde podríamos aseverar un principio de confianza (que excluya responsabilidad)? Antes de responder, tiene que quedar claro que la confianza se basa en el conocimiento de una situación: yo confío en que A puede hacer X porque conozco que A tiene la habilidad para hacer X. En tal sentido, la respuesta a la pregunta tiene que incorporar la correcta comprensión del riesgo permitido. De tal modo, el principio de confianza operaría en aquellas situaciones en donde parece sensato confiar, pero un análisis más detallado hubiese indicado que no lo era. Y parecía sensato porque el rol que desempeña el agente exige tener a la vista ciertos conocimientos para determinar si era razonable o no confiar en el otro. Si atendiendo a ese conocimiento era sensato confiar, pero profundizándolo no lo era, entonces descartamos su responsabilidad por imprudencia porque actuó conforme a lo que el derecho exigía para su ámbito, siendo supererogatoria la obtención de mayores conocimientos. El ordenamiento tolera cierta incapacidad en la evitación de resultados lesivos dado que es imposible que el sujeto tenga todo a la vista para decidir si confía o no. De forma que si para llegar a la conclusión que no era cuidadoso confiar en el comportamiento de otro era necesario adquirir un conocimiento superior al exigido según el rol que desempeña el agente, cualquier responsabilidad a título imprudente resulta excluida: el mismo ordenamiento está diciendo que se puede confiar.

De ahí que el principio de confianza tenga el mismo contenido que el riesgo permitido pero enfocado en la actuación de otros. Nótese, entonces, que el principio de confianza también es secundario frente a la imprudencia: son las exigencias de cuidado las que configuran la posibilidad de confianza, de modo que el principio de confianza opera allí donde esas exigencias encuentran su límite. Toleramos un margen de error sobre la actuación de los otros, lo que cuenta como una cierta incapacidad de acción, porque no es posible exigir control absoluto sobre la posibilidad de riesgo de los demás.

\section{Recapitulación}

Se podrían resumir los planteamientos expuestos en dos ideas. En primer lugar, la noción de riesgo permitido, formulada por una teoría de la imputación objetiva, se preocupa de elementos y problemas irrelevantes desde el punto 
de vista de la imputación jurídico penal, pues nunca es interesante revisar las ventajas y desventajas generales que puede generar un determinado comportamiento, ya que lo único interesante es si ese comportamiento realiza los elementos que el legislador ha estimado como relevantes tipificándolos en una norma penal. Este déficit argumentativo del riesgo permitido en el seno de esta teoría está directamente relacionado con lo problemático que resulta sentar un filtro de imputación que prescinda de las características individuales del sujeto que se trata de imputar, tomando como referencia simplemente un ciudadano con conocimientos y capacidades promedio ${ }^{81}$. Si el derecho penal analiza el comportamiento de un agente en atención a las normas pertinentes, entonces debiese ser ese agente (con sus conocimientos y capacidades) el único sujeto que se va a analizar.

Sin embargo, aún es posible rescatar al concepto de riesgo permitido de las dificultades ya expuestas. Y la posición sistemática hacia donde debe ser redirigido es a la imputación a título de imprudencia: cuando comprobamos que el eventual autor carece de la capacidad de evitar la conducta típica, entonces la determinación de la exigencia de cuidado resulta medular para fundar la conexión entre el sujeto y el comportamiento. Sin entrar en la discusión sobre el contenido de esa exigencia de cuidado, afirmar su establecimiento implica fijar un límite respecto de los riesgos por los cuales se hará responsable a un agente y los riesgos que tendrán que ser asumidos por la sociedad. Estos últimos son riesgos permitidos en atención a una cierta incapacidad de acción tolerada normativamente y que, por ende, no pueden ser atribuidos porque no existe capacidad individual de evitación a su respecto.

De tal forma, el ámbito en que una correcta comprensión del riesgo permitido alcanza su mayor rendimiento práctico es respecto a la actuación según rol. Porque el rol del agente no puede ser el elemento determinante para afirmar o descartar el eventual quebrantamiento imputable de una norma ${ }^{82}$. Sin embargo, la noción de rol sí resulta interesante a efectos de establecer las medidas de cuidado que le son exigibles a un determinado sujeto. De tal modo, aquellos riesgos que escapan a las exigencias de cuidado del sujeto de acuerdo a la posición en que actúa tienen que ser entendidos como riesgos permitidos. Lo relevante no es, por tanto, el rol per se sino cómo ese rol influye en las medidas que deben ser tomadas para asegurar la capacidad de evitación futura. El riesgo permitido, entonces, cumple la función de diferenciar entre los riesgos que tienen relevancia jurídico-penal, porque el sujeto estaba obligado a desarrollar

${ }^{81}$ Para profundizar sobre una crítica a la teoría de la imputación objetiva en general, véase KINDHÄUSER (2008), pp. 12 y ss.

${ }^{82}$ Véase JakoBs (1997b), pp. 211 y ss., 214 y ss.; Jakobs (1995), pp. 251 y ss. 
medidas para controlarlos, y aquellos riesgos que el ordenamiento no espera ni exige su control. Ni más ni menos, evidencia el lugar donde el derecho penal se rinde a la facticidad.

\section{BiBLIOGRAFÍA CITADA}

Corcor BiDAsolo, Mirentxu (1989): El delito imprudente. Criterios de imputación del resultado (Barcelona, PPU).

Etcheberry, Alfredo (1998) Derecho Penal, Tercera Edición (Santiago, Editorial Jurídica), tomo I.

ETCHeBERRY, Alfredo (2002): El derecho penal en la jurisprudencia (sentencias 1875-1966) (Santiago, Editorial Jurídica, reimpresión), tomo I y tomo IV.

Garrido Montt, Mario (2005): Derecho Penal. Parte Especial, Cuarta Edición (Santiago, Editorial Jurídica), tomo II.

HRUSCHKA, Joachim (2009a): "Actio libera in causa y autoría mediata", en su: Imputación y Derecho Penal (Montevideo/ Buenos Aires, B de F), pp. 199-216.

HRUSCHKA, Joachim (2009b): "La imputación ordinaria y extraordinaria en Pufendorf", en su: Imputación y Derecho Penal (Montevideo/ Buenos Aires, B de F), pp. 51-102.

HRUSCHKA, Joachim (2009c): "Reglas de comportamiento y reglas de imputación", en su: Imputación y Derecho Penal (Montevideo/ Buenos Aires, B de F), pp. 11-30.

JAKOBS, Günther (1997a): "El delito imprudente", en su: Estudios de derecho penal (Madrid, UAM y Civitas), pp. 167-196.

JAKOBS, Günther (1997b): "La imputación objetiva, especialmente en el ámbito de las instituciones jurídico penales del riesgo permitido, la prohibición de regreso y el principio de confianza", en su: Estudios de derecho penal (Madrid, UAM y Civitas), pp. 209-222.

JAKOBS, Günther (1995): Derecho Penal, parte general, Segunda edición (Madrid, Marcial Pons).

KINDHÄUSER, Urs (2013): “¿Qué es la imprudencia?”, en: Mañalich (dir.), La ciencia penal en la Universidad de Chile. Libro homenaje a los profesores del departamento de ciencias penales de la facultad de Derecho de la Universidad de Chile (Santiago, Facultad de Derecho, Universidad de Chile), pp. 217-228.

KINDHÄUSER, Urs (2011): "Acción y norma en el derecho penal" en: Kindhäuser y Polaino-Ortz, Normativismo en derecho penal (Chacó, ConTexto), pp. 69-99.

KINDHÄUSER, Urs (2008) "El tipo subjetivo en la construcción del delito", en: InDret (4/2008). 
KINDHÄUSER, Urs (2007) "El denominado riesgo no permitido", en su: Crítica a la teoría de la imputación objetiva y función del tipo subjetivo. Tres Estudios (Lima, Grijley), pp. 48-86.

KINDHÄUSER, Urs (1996): "Imprudencia y riesgo permitido", en su: Derecho penal de la culpabilidad y conducta peligrosa (Bogotá, Universidad Externado de Colombia), pp. 94-140.

Mañalich, Juan Pablo (2014): Norma, causalidad y acción (Madrid, Marcial Pons).

Mañalich, Juan Pablo (2013): "Normas permisivas y deberes de tolerancia", en La antijuridicidad en el derecho penal (Montevideo/Buenos Aires, B de F).

Mañalich, Juan Pablo (2011): "El delito como injusto culpable. Sobre la conexión funcional entre el dolo y la consciencia de la antijuridicidad en el derecho penal chileno", en: Revista de Derecho (volumen XXIV), pp. 87-115.

Mañalich, Juan Pablo (2010): "Norma e imputación como categorías del hecho punible", en: Revista de Estudios de la Justicia (No 12), pp. 169-190.

Molina, Fernando (2011): "Dolo eventual e imprudencia con representación en los delitos de tránsito", en: Doctrina y Jurisprudencia Penal (volumen VI). Disponible en: LegalPublishing on line, Cita CL/DOC/1209/2013 [visitado el 24/09/2014].

Ovalle, Germán (2011): "Imprudencia y cognición", en: Doctrina y Jurisprudencia Penal, volumen IV. Disponible en: LegalPublishing on line, Cita CL/ DOC/135/2011 [visitado el 24/09/2014].

Pérez del Valle, Carlos (2012): La imprudencia en el derecho penal. El tipo subjetivo del delito imprudente (Barcelona, Atelier).

PuPPE, Ingeborg (2008): "El resultado y su explicación causal en el derecho penal", en: InDret (4/2008), 47 pp.

Ragués I Valles, Ramón (1999): El dolo y su prueba en el proceso penal (Barcelona, Bosch Editor).

Raz, Joseph (1986): Razonamiento práctico (Ciudad de México, Fondo de Cultura Económica).

Raz, Joseph (1975): Practical reasons and norms (Oxford, Oxford University Press).

Rosas, Juan Ignacio (2011): "La delimitación del deber de cuidado en la imputación de responsabilidad por imprudencia médica", en: Doctrina y Jurisprudencia Penal (volumen V). Disponible en: LegalPublishing on line, Cita CL/DOC/1210/2013 [visitado el 24/09/2014].

Roxın, Claus (1997): Derecho Penal, parte general (Madrid, Civitas, tomo I). 
Silva SÁnchez, Jesús María (2013): "Interrupción de cursos salvadores ajenos dentro de la propia esfera de organización: un problema de justificación", en: Mañalich (dir.), La ciencia penal en la Universidad de Chile. Libro homenaje a los profesores del departamento de ciencias penales de la facultad de Derecho de la Universidad de Chile (Santiago, Facultad de Derecho, Universidad de Chile), pp. 229-248.

Van Weezel, Álex (2012): "El dolo eventual como espacio de discrecionalidad", en: Doctrina y Jurisprudencia Penal (Volumen VII). Disponible en: LegalPublishing on line, Cita CL/DOC/1203/2013 [visitado el 24/09/2014].

VAN WeEZEL, Álex (2011): “Parámetros para el enjuiciamiento de la infracción al deber de cuidado en los delitos imprudentes", en su: Límites de la imputación penal. Estudios 2000-2010 (Bogotá, Universidad Externado de Colombia), pp. 127-149.

Van Weezel, Álex (1999): "Parámetros para el enjuiciamiento de la infracción al deber de cuidado en los delitos imprudentes", en: Revista Chilena de Derecho (Volumen XXVI, № 2), pp. 323-336.

VON WRIGHT, Georg Henrik (2008): "Inferencia práctica", en: Praxis Filosófica (26), pp. 303-321. 